\title{
DE PROFECÍA A LEYENDA: INVENCIÓN Y REINVENCIONES DE LA PRINCESA PAPANTZIN, 1558-1921
}

\author{
David Carbajal López \\ Universidad de Guadalajara
}

$\mathrm{E}_{\text {entonces, Mariano Azuela González, publicó un homenaje }}^{\text {n 1942, uno de los más célebres escritores mexicanos de }}$ a un distinguido coterráneo suyo, el padre Agustín Rivera. Más que una biografía sistemática, era una serie de anécdotas sobre su vida y obra relatadas con la libertad propia del novelista. En una de ellas, titulada "Censura eclesiástica" contaba cómo "una noche [de 1880] llegó muy alarmado el juez de letras don Manuel Cabral, amigo suyo", al domicilio de Rivera en el corazón de Lagos de Moreno, Jalisco, para notificarle que en la parroquia se había recibido la censura de su Compendio de la historia antigua de México (1878)..$^{1}$ Azuela destacaba la tranquilidad de su biografiado al saber la noticia: ante el "espanto" de Cabral, quien de inmediato preguntó cuál sería su reacción, Rivera se habría limitado a responder "Ya veremos". El propio Azuela se ocupó enseguida de explicar el motivo de la censura, no sin antes

Fecha de recepción: 23 de febrero de 2020

Fecha de aceptación: 24 de septiembre de 2020

${ }_{1}$ Azuela, El padre, pp. 102-104. Todas las citas que aparecen en este párrafo proceden de estas páginas. 
apuntar que en realidad se debía a un viejo problema personal entre el autor y el censor, Luis Barbosa, quien "ha leído ya 145 páginas sin encontrar hueso, cuando de pronto hace un gesto de regocijo y comienza a garrapatear". El problema estaba en los comentarios que incluía el Compendio sobre "la leyenda de la princesa Papantzin”, en la que un ángel le declaraba que las almas de sus antepasados, los aztecas, estarían en el infierno, lo que valió para que el sacerdote laguense lo calificara de "mal teólogo".

Volveremos en su momento sobre las diferencias entre Rivera y Barbosa, aquí simplemente nos sirve para recordar la importancia que tenía ese relato en las últimas décadas del siglo xIX. En nuestros días, por el contrario, a pesar de que estas líneas se escriben justo cuando se está conmemorando el quinto centenario de lo que conocemos como la conquista de México, la princesa Papantzin ya no es particularmente recordada, salvo por quienes se especializan en ciertas materias de historia y literatura. Rivera, en cambio, había elaborado sus consideraciones a partir de tres textos que fueron muy importantes para la naciente comunidad intelectual mexicana del siglo XIx, dos de traducción relativamente reciente entonces, los del padre Francisco Xavier Clavijero (Historia antigua de México y de su conquista, 1844) y del estadounidense William Prescott (Historia de la Conquista de México, 1844-1846), además de una obra más antigua, la de fray Juan de Torquemada (Monarquía indiana, 1615). Salvo el segundo, se trataba de crónicas escritas por autores que habían vivido y trabajado, no en México como nación y Estado según se concebía desde 1821, sino en el reino de Nueva España, integrante de la Monarquía hispánica. Torquemada había escrito en los primeros años del siglo xviI, Clavijero en la segunda mitad del xviII, y, sin embargo, no fueron realmente los primeros en contar la "leyenda de la princesa Papantzin”, por utilizar los términos de Azuela, pues todavía tenemos que remontarnos a otro cronista un poco más antiguo: fray Bernardino de Sahagún. 
En este artículo nos interesa, en principio, volver sobre esos textos, y seguir con precisión la forma en que se fue construyendo el relato de Papantzin en tiempos novohispanos, como profecía de la conquista y representación de un modelo femenino casi monástico. Pero este ejercicio, que ya ha sido materia de otros estudios, ${ }^{2}$ nos ayuda más bien a ponderar los cambios, ya no tanto del relato cuanto de su significado y sentido, que tuvieron lugar en el siglo XIX y hasta los primeros años del xx. Rivera no fue el primero en cuestionar alguno de sus aspectos, antes bien, es significativo que ya Azuela se refiriera sin problema alguno a una "leyenda" y no a un hecho histórico. Tras la independencia, aunque hubo autores que insistieron en su historicidad, como Carlos María de Bustamante, fue progresivamente desplazada de la memoria nacional por algunos de sus más destacados constructores, como el propio Rivera, Manuel Orozco y Berra y Guillermo Prieto. Ese desplazamiento iba también en demérito de la representación de los aztecas, y en particular de su emperador, Moctezuma, cuya superstición se confirmaba con la creencia en el milagro de la resurrección de la princesa.

Mas Papantzin no fue simplemente enterrada, sino que resucitó una vez más, pero ahora como personaje de la cultura nacional en la pluma de literatos como Emilio Rey, José María Roa Bárcena, José Peón Contreras y, sobre todo, José María Marroquí. Convertida por ellos en "leyenda mexicana”, la princesa adquiría nuevos matices, correspondientes a los modelos de género que los intelectuales imponían a las mujeres de la época. Tal es, podemos decir desde ahora, el interés que tiene volver sobre la historia de las historias de la princesa Papantzin, pues nos muestra los elementos comunes y las diferencias entre los discursos sobre los pueblos prehispánicos y sobre las mujeres propios del catolicismo del siglo xvi y el liberalismo del xIx. Esto es, nos

2 En particular el de Ragot, “Mémoire espagnole”. 
permite analizar aspectos del proceso de secularización que apenas están siendo atendidos por la historiografía de lo religioso y lo político, como los cambios en las representaciones de género y de etnia.

Comencemos pues nuestro recorrido, remontándonos a los mediados del siglo XVI, a la obra del religioso franciscano fray Bernardino de Sahagún.

\section{MENSAJERA DE TLÁLOC O PROFETISA ENCLAUSTRADA}

Nuestro primer cronista, el padre Sahagún, dista mucho de ser un desconocido para la historiografía mexicanista, antes bien se trata tal vez del evangelizador del siglo xvi cuyos datos son mejor conocidos. ${ }^{3} \mathrm{Ha}$ pasado a la historia fundamentalmente porque, para colaborar con esa labor de aculturación, comenzó, desde finales de la década de 1550, una amplia investigación de las antiguas "idolatrías" de los pueblos del centro del reino de Nueva España, evidentemente - como declara al inicio de su monumental obra - para que sirviera de herramienta para destruirlas. "El médico no puede acertadamente aplicar las medicinas al enfermo sin que primero conozca de qué humor o de qué causa procede la enfermedad", ${ }^{4}$ fue la contundente primera frase de su crónica.

Como se sabe hoy gracias a una amplia serie de trabajos, ${ }^{5}$ ese esfuerzo del franciscano se hizo desde las redes conceptuales de la teología cristiana, que de por sí tenían clara una caracterización de los pueblos no occidentales, confirmada constantemente

${ }^{3}$ Para la biografía de Sahagún, véase León Portilla, Bernardino de Sahagún.

${ }^{4}$ Sahagún, Códice Florentino, vol. 1, f. 1.

${ }^{5}$ En particular, y sólo por citar algunos: Rozat, Indios reales; LóPEz, "Discursos historiográficos"; SEgundo, "Conquista y reinterpretación"; SEgundo, Historia y mirada. 
en la experiencia de los frailes. ${ }^{6}$ Por ello, su obra, aunque redactada tanto en náhuatl como en castellano, no puede concebirse como una fuente transparente de conocimientos sobre las culturas prehispánicas, ni es de extrañar que contenga innumerables elementos de la cultura occidental aplicados a los pueblos mesoamericanos.

En la primera recopilación de los materiales reunidos por el franciscano y sus colaboradores, conocida como los Primeros memoriales (1558-1561), aparece la primera versión de la historia que nos interesa, pero su protagonista ni siquiera lleva ("todavía”) el nombre de Papantzin, sino el de Quetzalpétlatl. En cambio, se definía ya como una "historia milagrosa o profecía", que habría tenido lugar "diez o doce años antes que viniesen los españoles a esta tierra", 7 según se apuntaba en español antes de comenzar el relato en náhuatl. Ahora bien, no se trata de una historia tranquila ni ejemplar: es la historia de la nuera del gobernante de Tlatelolco, que muere víctima de la agresión de su suegro. Hasta donde sabemos sólo $\operatorname{Ragot}^{8}$ se ha detenido a analizar esta primera versión, pero más que la violencia contra la protagonista ha subrayado que, al morir concretamente de diarrea, fue vinculada a Tláloc, por lo que en lugar de ser incinerada fue enterrada en una profunda tumba donde permaneció cuatro noches. Esto es, se trata de un punto decisivo para establecer que se trata de un relato con "elementos prehispánicos". Como indica en su conclusión dicha autora, "el texto [...] debía constituir aun en la época un relato significativo para un indígena, incluso aculturado". ${ }^{9}$

\footnotetext{
${ }^{6}$ Un buen ejemplo es también el padre Las Casas. Bernard y GruZinski, De la idolatría, pp. 38-79.

7 Sahagún, Primeros memoriales, p. 179.

8 RAGOT, "Mémoire espagnole”, p. 11, señala: "la manera de morir era, generalmente, reveladora del destino del difunto en el otro mundo".

9 Ragot, "Mémoire espagnole", p. 18.
} 
A falta de la foja final de la historia, es la mención de las "cuatro noches y cuatro días" que pasó enterrada lo que nos indica que salió de su tumba, ${ }^{10}$ pero no sabemos exactamente cómo ni por qué. En cambio, tenemos sus visiones del más allá: guiada por un joven "deforme", recorrió la tierra de los muertos. Antes de iniciar su camino, Quetzalpétlatl entonó un canto, tlacateculutl icuic, es decir, devil song o "canto del hombre-búho", ${ }^{11}$ en que pide que la muerte dure sólo una noche, pero la invocación inicial alude a joyas o collares y a un escudo. La oscuridad de estos símbolos para un lector de tradición occidental podría hacer pensar que se trata efectivamente de un relato con elementos prehispánicos, a pesar de que el personaje del "hombre-búho" también ha sido relacionado con la diabolización de las deidades indígenas y con la zoología del más allá cristiano. ${ }^{12}$

Ahora bien, el más allá de este relato es un espacio compartimentado. La protagonista atravesó sucesivamente grandes llanuras, un espacio rocoso, el lugar donde residen mujeres que tejen y finalmente el Tlalocan, rodeado de niebla, donde se encontraban los muertos por el rayo o por el agua, y desde donde alcanzó a ver un espacio donde yacían niños pequeños, así como otro, más lejano, donde se encontraban los antiguos gobernantes. Aunque el espacio de los niños no deja de recordar al limbo de los infantes de la tradición cristiana, cabe reconocer que el trayecto no incluye ni los espacios subterráneos ni el detallado refinamiento de pecados y torturas que caracterizaba ya al infierno medieval. ${ }^{13}$ La única referencia que queda del aspecto profético del relato es que Tlalocantecuhtli le entregó un "pequeño cofre" y un "recipiente de calabaza" con los cuales podría "remediar" a "quienes están en la miseria". ${ }^{14}$

10 Sahagún, Primeros memoriales, p. 180.

11 Esta última es la traducción de Johansson, “La Ley de Topiltzin”, p. 153.

12 López, "Imaginario franciscano".

13 BASCHET, La civilización feudal, pp. 435-438.

14 Sahagún, Primeros memoriales, p. 183. 
La mensajera de Tláloc, y es lo que más nos interesa resaltar, no llegó a la versión final de la obra del padre Sahagún. De hecho, la relación entre el párrafo sin número del segundo capítulo de los Primeros memoriales con el breve relato incluido en el primer capítulo del libro octavo del Códice Florentino no es evidente de por sí, y obliga a acotar que "parece probable", ${ }^{15}$ o en los términos de López Austin: "pudo haber tal vez algo más, recogido de otro manuscrito junto con esta última historia, pues parece que los textos fueron mezclados $[\ldots ..]{ }^{16} \mathrm{Y}$ es que en lugar de encontrar la historia de la resucitada en los libros dedicados a las creencias en el más allá, aparece en uno dedicado a contar hechos bélicos y maravillosos ocurridos bajo cada gobernante. Así, en tiempos del segundo Moctezuma

[...] una mujer vecina de México-Tenochtitlan murió de una enfermedad y fue enterrada en el patio, y encima de su sepultura pusieron varias piedras, la cual resucitó después de cuatro días, con grande miedo y espanto de los que se hallaron presentes allí, porque se abrió la sepultura y las piedras se derramaron lejos. Y la dicha mujer que resucitó fue a casa de Motecuhzoma y le contó todo lo que había visto y le dijo: la causa por la que he resucitado es para decirte que en tu tiempo se acabará el señorío de México y tú eres el último señor; porque vienen otras gentes y ellas tomarán el señorío de la tierra y poblarán a México. Y la dicha mujer que resucitara, después vivió otros veintiún años y parió un hijo. ${ }^{17}$

Relato más breve, su protagonista pasa de nuera del señor de Tlatelolco a anónima vecina de Tenochtitlan y, sobre todo, su historia es la de una profecía al monarca sobre el final de su

15 Anderson, “Los 'Primeros Memoriales' ”, p. 69.

16 López Austin, "Estudio acerca del método", p. 370.

17 Sahagún, Códice Florentino, vol. 2, libro 8, fs. 2v.-3. 
reinado. La resurrección propiamente dicha cobra un aspecto más espectacular y comienza a asociarse al miedo. Casi sobra decir que no es el único anuncio profético de la llegada de los europeos que aparece en la obra de Sahagún; de hecho, existe una serie completa de "presagios de la Conquista"18 en los cuales bien podría haberse incluido este incidente, como hizo más tarde el padre fray Juan de Torquemada.

La obra de Sahagún permaneció inédita hasta el siglo xIx; en cambio, el trabajo del padre Torquemada logró publicarse a principios del XvII, teniendo una segunda edición a principios de la centuria siguiente. Hoy en día su autor es menos conocido que Sahagún, ${ }^{19}$ pero se sabe que fue guardián del convento de Santiago Tlatelolco, y que ahí comenzó a redactar su Monarquia indiana. Nombrado cronista de su provincia en 1609, recibió la autorización para publicar su obra en 1612, cuando ya era guardián del convento de Tlaxcala, y finalmente la primera edición salió impresa en Sevilla en 1615, cuando se desempeñaba ya como provincial del Santo Evangelio.

De su extensa crónica, nos interesan concretamente los dos últimos capítulos del libro II. Al igual que en el caso de Sahagún, se trata del relato de la historia de "los mexicanos" desde su salida de Aztlán, centrado en la serie de sus gobernantes, sus guerras $\mathrm{y}$, finalmente, "los prodigios y señales que tuvieron para su destrucción y acabamiento" ${ }^{20}$ Como buen franciscano, al igual que Sahagún, Torquemada escribía una historia cuyo sentido era dictado por la Divina Providencia. Afirmaba sin dudar que "en casos arduos y negocios dificultosos, que por justos juicios de Dios acontecen en el mundo, suele haber señales y prodigios que pronostican estos acontecimientos". ${ }^{21}$ Ofrecía como prueba las señales que precedieron la caída de Jerusalén conforme a la obra

18 Sahagún, Códice Florentino, vol. 3, libro 12, fs. 1-3.

19 Al respecto León Portilla, "Biografía”.

20 Torquemada, Monarquía indiana, vol. I, p. 107.

21 Torquemada, Monarquía indiana, vol. I, p. 317. 
del historiador judío Flavio Josefo, antes de citar los presagios de la Conquista, a los que dedica el capítulo XC. Enseguida, a partir de "pinturas antiguas" y de un texto por escrito remitido a España, ${ }^{22}$ dedicaba el último capítulo del libro al presagio más claro, que como en los Primeros memoriales, habría ocurrido "diez años antes" de la llegada de los conquistadores.

Quetzalpétatl se convierte en Papan, hermana de Moctezuma y viuda del señor de Tlatelolco, en cuya casa siguió viviendo. Como buena princesa, "era servida de señores y plebeyos con mucho respeto y cuidado", lo que no evitó que muriera "de una grave enfermedad" que no se especifica. De nuevo es enterrada y no incinerada, pero ya no en un patio sino en un jardín con baños, y no dura en su tumba sino hasta el día siguiente, cuando una niña de su familia la descubre sentada a la orilla de la alberca junto al baño. El miedo se hace presente nuevamente, la niña llama a la "mayordoma" de Papan, que al verla "cobró grande espanto y cayó en tierra amortecida", "otras dos dueñas de casa” a las que recurrió también "cobraron temor" al verla. ${ }^{23}$ Por medio del "rey de Tetzcuco", Nezahualpilli, Papan contacta con Moctezuma - quien también reacciona asustado al verla-, a quien transmite, como en el Códice Florentino, su experiencia en el más allá. Su guía ya no es deforme sino un angelical "mancebo vestido de hábito largo, blanco como un cristal [...] su rostro resplandeciente como una estrella, el cual tenía en la frente una señal $[\ldots]$ y con unas alas de pluma rica $[\ldots] ” .{ }^{24}$

La profecía vuelve al tema del recorrido por el más allá, pero se borran todos los rasgos del Tlalocan de los Primeros memoriales en beneficio, aquí sin duda alguna, de la geografía cristiana medieval. La visión de Papan según Torquemada podría bien sumarse a los ejemplos que reunió Le Goff en La naissance $d u$

22 Torquemada, Monarquía indiana, vol. I, p. 327.

23 Torquemada, Monarquia indiana, vol. I, pp. 324-325.

24 Torquemada, Monarquía indiana, vol. I, p. 326. 
Purgatoire. ${ }^{25}$ En efecto, la princesa llega a un valle "muy espacioso y ancho", surcado por "un caudaloso río", que evidentemente hace de frontera con el mundo de los muertos. El ángel la detiene al tratar de atravesarlo y la lleva a recorrer lo que se entendía era el infierno, un lugar donde entre "gemidos muy dolorosos" yacían "cabezas y huesos" que eran de "nuestros antepasados". ${ }^{26}$ Desde luego, vio a los demonios, "personas negras, con cuernos en la cabeza y los pies de hechura de los venados o ciervos", ocupados en construir "una casa" donde habrían de encerrar a los caídos en la conquista; vio también la llegada en unos navíos de los "hijos del sol". En fin, recibió el anuncio de que ella misma vería "vueltas las cosas en otro estado y gozar de la fe que aquellas gentes traían", e incluso ella misma sería "guiadora de las gentes" al bautismo. Desde luego, Moctezuma no cree en la profecía, lo que sirve a Torquemada para finalizar casi con una moraleja doble contra los "necios y obstinados", en contraste con "doña María Papan”, que en cambio pertenecía al "número de los predestinados".

Destaquemos en particular que en este punto la profecía adquiere un matiz didáctico, pues la princesa resucitada se convierte en ejemplo de vida. La escueta descripción de su nueva vida estuvo caracterizada por dos prácticas asociadas a una de las virtudes cardinales, la templanza, y al modelo por excelencia para la mujer cristiana entonces, la vida monástica: vivió "recogida y no comía más que una vez al día”, esto es, estaba, ya que no propiamente enclaustrada, al menos encerrada, y ayunaba. Lo primero era fundamental, se trata del acto virtuoso por excelencia esperado del género femenino en la tradición cristiana desde tiempos medievales. El ayuno tampoco era asunto menor, ya lo señalaba Tomás de Aquino, era un acto virtuoso porque "sirve

${ }^{25}$ En particular Le Goff, La naissance, pp. 154-166.

26 Torquemada, Monarquia indiana, vol. I, pp. 326-327. Todas las citas siguientes en este párrafo proceden de esta referencia. 
para frenar la concupiscencia", "hace que la mente se eleve a la contemplación de lo sublime" y "es bueno para satisfacer por los pecados". ${ }^{27} \mathrm{Al}$ caracterizar así la "vida de buena cristiana" de una princesa beneficiada de la predestinación divina, la aproximaba a la vida contemplativa de una orden religiosa.

En el siglo xviII, el padre Francisco Xavier Clavijero apenas si modificó algunos puntos de la historia. Lo más notorio es el cambio de nombre de la protagonista: Papan se convirtió en Papantzin. En cambio, subsistió buena parte del contexto. Aunque estaba "muy lejos de pensar que todo lo que hallamos escrito" sobre los presagios era "digno de crédito", 28 Clavijero no los cuestionaba de forma radical. Más aún, su origen no podía ser sino divino o demoníaco: "aquel maligno espíritu, enemigo capital del género humano", habría podido "conjeturar los progresos marítimos de los pueblos de Oriente”, y se lo manifestó a esos pueblos para confirmar "la errónea persuasión de su pretendida divinidad". En cambio, la profecía de Papantzin era de origen divino pues estaba dirigida a "disponer sus espíritus a la admisión del Evangelio". ${ }^{29}$

Clavijero expuso el relato retomando la versión de Torquemada, de quien repitió las fuentes ("algunas pinturas de aquella nación”), haciendo algunos cambios de matiz. Fue el jesuita exiliado quien utilizó ya directamente el término "princesa mexicana" para referirse a Papantzin y quien introdujo una cita directa del ángel que hacía más explícitos dos puntos que en Torquemada se prestaban a alguna ambigüedad. Primero, el sitio en que la princesa vio a sus antepasados era el infierno pues era lugar de tormentos eternos para sus antepasados, y segundo, "la fe" se revelaba ya como "la noticia del verdadero Dios, criador del cielo y de la tierra". Desde luego, Papantzin se consagra

${ }^{27}$ Aquino, Suma teológica, parte II-IIae, cuestión 147, art.1

28 Clavijero, Historia antigua, p. 137.

29 Clavijero, Historia antigua, p. 138. 
como "perfecto modelo de virtudes cristianas", conforme al modelo monástico. ${ }^{30}$

Así pues, la mensajera de Tláloc de mediados del siglo xvi, en cuya historia podía haber elementos prehispánicos, fue transformada por los padres Sahagún, Torquemada, sobre todo, y Clavijero, en una profetisa beneficiada de la predestinación divina, un papel al que correspondía cabalmente con sus virtudes. Aunque hasta ahora no hemos encontrado su profecía mencionada en otros textos novohispanos, la difusión que tuvieron los libros de Torquemada y Clavijero hace pensar que la princesa resucitada seguía viva, por así decir, y cumpliendo su papel de legitimadora de la conquista y de un modelo femenino claustral, hasta casi el final de la época virreinal. Nos lo confirma un documento del momento en que la legitimidad de la conquista fue puesta en duda: la proclama de un clérigo michoacano contra el movimiento insurgente, fechada en abril de 1811. En ella criticaba la lucha independentista usando una serie de preguntas retóricas a manera de reclamo, entre ellas: " ¿esta es la recompensa que reciben unos hombres a quienes el cielo mismo ha hecho señores de estas tierras?”. En nota al pie se citaba como explicación de la pregunta "el discurso de la princesa Papantzin resucitada milagrosamente".${ }^{31}$ No es de extrañar entonces que, después de 1821, comenzaran los cuestionamientos en torno a este relato profético.

\section{TESTIMONIO DE SUPERSTICIÓN}

En las primeras décadas de vida independiente, Carlos María de Bustamante, antiguo insurgente, fue uno de los principales promotores de la recuperación de la memoria de la época prehispánica. A ese respecto, se ocupó de la publicación de las crónicas de

30 Clavijero, Historia antigua, p. 139.

31 Suplemento a la Gazeta del Gobierno de México, 53 (3 mayo 1811), p. 400. 
los evangelizadores, en particular de la del padre Sahagún, cuya Historia general fue publicada por la imprenta de Alejandro Valdés en 1829. En el pasaje que ya hemos citado sobre la mujer resucitada, Bustamante agregó una nota al pie identificándola como Papantzin, remitiendo a la obra de Clavijero, quien "refiere este hecho maravilloso y con buena crítica lo tiene por cierto e incontestable". ${ }^{32} \mathrm{El}$ mismo uso de Clavijero como autoridad aparece en sus Mañanas de la Alameda, ${ }^{33}$ reiterando el carácter histórico del relato, e incluso su argumento sobre el origen de las profecías. Esto es, todavía en esos primeros años después de la independencia, era posible tratar de incluir en la escritura de una historia nacional profecías de la tradición católica.

Hasta donde hemos podido averiguar, el primero en criticar esa nota de Bustamante fue el historiador estadounidense William H. Prescott. ${ }^{34}$ Para él las profecías de la conquista eran sólo "cuentos extraordinarios", en los que sin embargo "no es cosa tan difícil descubrir algunos vislumbres de verdad”, decía, atribuyéndolos a rumores de la presencia europea en el Caribe. Respecto de "la resurrección de Papantzin", aclaró en nota al pie que prefería no hablar del tema, se entiende que por tratarse del menos verosímil “en nuestro siglo”. La naciente historiografía nacional decimonónica compartió mayormente esta postura parcialmente crítica respecto de las profecías de la conquista y en particular sobre el caso que aquí nos ocupa, aunque mayormente sin cuestionar su origen prehispánico.

Es a mediados de siglo cuando se hace evidente el desplazamiento de la princesa Papantzin en la historia nacional, pues se presenta su historia fundamentalmente para criticarla y para insistir en la credulidad de los aztecas, la de Moctezuma en particular. Así, en un artículo sobre la antigua ciudad de México del

32 SAHAgún, Historia general, t. II, p. 270.

33 Bustamante, Mañanas de la Alameda, t. II, pp. 167 y 271.

34 Prescott, Historia de la conquista, t. I, p. 226. 
Diccionario universal de historia y geografía, José María Lafragua (1854) escribía contundente: “este suceso [...] tendrá poco o ningún precio a los ojos de la crítica”, pero "para hombres tan supersticiosos como los mexicanos [...] debió ser un golpe verdaderamente mortal". ${ }^{35} \mathrm{El}$ emperador, que en las crónicas de Torquemada y Clavijero era criticado por no haberle concedido validez a la profecía, ahora era caracterizado por un "fanatismo supersticioso”, como escribía José Fernando Ramírez (1864), quien también redujo "la pretendida resurrección de Papantzin" a una "conseja", de las "que más sirven para quitar la fe que para crearla” (p. 26). ${ }^{36}$ Pantaleón Tovar (1873) hacía una reflexión semejante: por una parte, "la superstición formaba el fondo del carácter de Motecuhzoma”, por otra, la historia "no puede aceptar como buenos esos milagros". ${ }^{37}$ Tovar fue de los pocos autores que cuestionaban el origen de éste y los demás milagros: incluso si estaban "descritos en los jeroglíficos", pues "muy bien pudo suceder que esas pinturas fueran hechas por los dominadores con posterioridad a la conquista, para imponer respeto y miedo", aunque esto no evitaba que hablara en términos del “ánimo supersticioso del pueblo conquistado". ${ }^{38}$

Más directo, Niceto de Zamacois pondría en labios del propio Moctezuma la evocación del "maravilloso aviso" de su hermana al momento de presentar sus consideraciones para jurar vasallaje al rey de España. Desde luego, acotaba que "es indispensable que lo que se creyó muerte en la princesa Papantzin fuese una catalepsia". ${ }^{39}$ También Manuel Orozco y Berra resolvía el punto "admitiendo un caso de catalepsia", reiterando la certeza de que los aztecas efectivamente esperaban "la venida de los hombres

\footnotetext{
35 Lafragua, “Ciudad antigua”, p. 789.

36 Ramírez, Bautismo de Moteubzoma, p. 26.

37 Tovar, "Moctezuma Xocoyotzin", p. 279.

38 Tovar, "Moctezuma Xocoyotzin", pp. 280-281.

39 Zamacois, Historia de Méjico, vol. 3, pp. 130-132.
} 
blancos". ${ }^{40}$ Menos conciliador, Guillermo Prieto se refería a la "leyenda absurda de la princesa Papantzin", que podía considerarse apenas una "vulgaridad", pero como en todos los anteriores autores, tenía sentido en el pueblo azteca: "para predisponer y acobardar al monarca, para que desahogasen su descontento los pueblos". 41

Lo mismo podía leerse en la prensa cuando se trataba de discursos cívicos y académicos. Así, al clausurar los cursos del Instituto de Campeche en 1866, Joaquín Baranda disertaba sobre la superstición y el temor que caracterizaban, según él, la poesía azteca, y evocaba de inmediato la creencia en que "los vaticinios de la princesa Papantzin iban a cumplirse". ${ }^{42}$ En la conmemoración de la independencia de 1872, el licenciado José Antonio Mateos se refería a las "pesadillas fantásticas de Papantzin", ${ }^{43}$ mientras que en 1878 la maestra Aurelia Mendizábal afirmaba que Moctezuma había pasado de ser un "valiente guerrero de alma grande" a un "ser pusilánime y débil" por su superstición, por las "respuestas de los agoreros" y porque "además se daba por cierta la resurrección de la princesa Papantzin". ${ }^{4}$ En suma, a pesar del esfuerzo inicial de Bustamante, el relato de la princesa resucitada no había logrado transitar de la profecía a la historia nacional, salvo como una prueba de la inferioridad cultural de los aztecas ante los españoles.

Mas entre todos los historiadores liberales de la segunda mitad del siglo xix en México, tal vez a quien causaba mayor problema el relato de la princesa era a uno que trataba de reconciliar

40 Orozco y Berra, Historia antigua, vol. 3, p. 474.

${ }^{41}$ Prieto, Lecciones de historia, pp. 37-38.

42 Baranda, Obras, p. 9.

43 José Antonio Mateos, "Discurso oficial pronunciado por el C. Lic. ... en el aniversario del 16 de septiembre de 1872”, El Siglo Diez y Nueve (16 sep. 1872), p. 2.

${ }^{44}$ Aurelia Mendizábal, "Disertación pronunciada por la señorita... en la oposición que tuvo lugar el 26 de octubre”, El Municipio Libre (13 nov. 1878), p. 2. 
liberalismo y catolicismo. En efecto, si alguien se detuvo a analizarlo e insistió en descalificarlo fue el clérigo y escritor público Agustín Rivera, hasta el punto de ganarse por ello una censura formal de la Arquidiócesis de Guadalajara, como hemos visto al inicio. La obra objeto de censura era resultado de su labor como profesor de historia en el Liceo de Varones de su natal Lagos de Moreno. Voluminoso texto de 447 páginas, estaba dividido entre los tiempos "antehistóricos" y los "históricos", separados por la fundación de Tenochtitlan. La segunda parte se dividía a su vez en dos libros, uno para la historia propiamente dicha y otro para la civilización bajo Moctezuma Xocoyotzin. Los relatos y descripciones se completaban además con capítulos dedicados a lo que el doctor Rivera llamaba "filosofía de la historia", las reflexiones generales sobre su escritura. Es justo al cierre del libro primero de la segunda parte y en uno de esos capítulos que abordó la historia de Papantzin, con el significativo subtítulo de "Falta de crítica en España y México en los siglos XVI, XVII y XVIII". 45

De nuevo, no se trataba de negar "la expectación universal de un hombre extraordinario" 46 entre los aztecas, sino sólo la realidad de los milagros, un tema que era muy querido de Rivera. Contra su veracidad, Rivera reunió en este caso un total de 12 observaciones. En ellas argumentaba a varios niveles. En primer lugar, había una cuestión antropológica: "los indios aun en el día tienen una imaginación muy exaltada, que revela su origen oriental” ${ }^{47}$ Respecto a la caracterización de lo asiático, había explicado ya en su Compendio de historia antigua de Grecia que los pueblos "de la descendencia jafética" (según el modelo del Génesis), los asiáticos, se habrían "civilizado más tarde" en virtud de su dedicación al nomadismo, mientras que semitas y

\footnotetext{
${ }^{45}$ Rivera, Compendio de la historia antigua de México, pp. 135-140.

46 Rivera, Compendio de la historia antigua de México, p. 136.

47 Rivera, Compendio de la historia antigua de México, p. 137.
} 
camitas, al establecerse en territorios más favorables al sedentarismo, lo habrían hecho antes. La civilización, afirmaba Rivera, requería no sólo de "paz y progreso", sino de "radicación en un lugar" al menos "en su infancia", 48 y la infancia estaba, precisamente, asociada a la imaginación. Desde luego, en las observaciones 2 a 4 había también una crítica de la credulidad de los españoles en "milagros supuestos". ${ }^{4}$

Enseguida, las observaciones 5, 6 y 10 hacían crítica de fuentes. Rivera cuestionaba los argumentos que Torquemada y Clavijero habían usado como testimonios del milagro, a saber, una información jurídica "que no se sabe cómo se hizo ni en qué tiempo", así como ciertas "pinturas", mas insistía en que estas últimas, como escrituras jeroglíficas, lejos de ser un testimonio cierto se prestaban a confusión. Notaba además la ausencia del relato en otras crónicas del siglo xvi, a pesar de que Clavijero tenía el hecho por "público y estrepitoso". En la observación séptima terminó por construir un relato "probable" del incidente: si Zamacois y Orozco y Berra habían hecho de la profetisa la víctima de una catalepsia, Rivera la consideró loca: la princesa simplemente "se creyó muerta y se hizo colocar en una gruta de su jardín a guisa de sepulcro". Al igual que Tovar, en las observaciones 7 a 10 no dejó de apuntar al uso político de los relatos de milagros. Papantzin, en su locura podía haber hablado "a su hermano de la caída de su monarquía”, pero estimaba que el tema del presagio de la Conquista no era sino un añadido posterior. Bien podía haber sido inventado por los indios, "para congraciarse" con los españoles "y aliviar de algunos modos el yugo de fierro que pesaba sobre su cuello", afirmaba haciéndose eco de la visión negativa de la dominación española; o al contrario, sería

${ }_{48}$ Rivera, Compendio de la bistoria antigua de Grecia, pp. 22-23.

49 Rivera, Compendio de la historia antigua de México, p. 138. 
obra de los españoles "para apoyar su conquista y dominación en una sanción divina". ${ }^{50}$

Ahora bien, en su última observación, Rivera dejó el campo de la historia para entrar al de la teología: "El espíritu que habló a Papantzin debe haber sido un mal teólogo, porque creyó que todos los que mueren en el gentilismo se condenan”. Estaba lejos de improvisar en la materia, antes bien repetía una proposición que había desarrollado con cierta amplitud en el tratado Concordancia de la razón y la fe (1876), aunque no sin alguna divergencia. En ese texto, había insistido en que la razón natural podía alcanzar el conocimiento de la ley natural y, por tanto, a pesar de la "ignorancia invencible" de la revelación, evitar la condena eterna. Los infieles en este caso, empero, "habiendo observado la ley natural no se salvan, sino que se van al limbo". ${ }^{51}$

En cambio, en nota al pie, ampliando lo dicho en su duodécima observación sobre el caso de Papantzin, concedió una excepción a esa regla, apoyado en las "Maximes de l'Église catholique sur le salut des hommes" del conde de Frayssinous. El también obispo de Hermópolis contestaba ahí a autores como Rousseau, a propósito de la condenación de los infieles, con la posibilidad de una "revelación especial" o de "impresiones interiores", o bien incluso algún otro "prodigio de misericordia" que le permitiría a un infiel alcanzar incluso la salvación eterna. De ahí que don Agustín pudiera declarar su creencia en que "algunos aztecas y otros americanos", que practicaban los sacrificios humanos "sólo por obedecer la ley civil", con deseo de la revelación y contrición por violar la ley natural, no sólo no se habían condenado ni estaban en el limbo sino que "reinan con Cristo eternamente", gracias a "inspiraciones interiores a la orilla de la tumba". ${ }^{52}$ Como puede verse, siendo crítico moderno

${ }^{50}$ Rivera, Compendio de la historia antigua de México, pp. 139-140.

${ }^{51}$ Rivera, Concordancia de la razón, p. 8.

52 Rivera, Compendio de la historia antigua de México, p. 140. 
de las apariciones y presagios, el padre Rivera no dejaba de creer ni en el limbo ni en la salvación casi milagrosa de los aztecas.

Fueron esta observación y su nota al pie las que ameritaron la censura de la mitra de Guadalajara, que confió la labor al párroco del Sagrario, Luis Barbosa. No podemos detallarla aquí, bástenos señalar dos puntos: en principio, que estimó contrario a la enseñanza católica afirmar que un idólatra podía haber estado en mejor situación para salvarse que un católico; esto es, esos "milagros asombrosos" de Rivera eran "rarísimos" ${ }^{33}$ Pero además había una cuestión política fundamental: salvar a idólatras que practicaban sacrificios humanos era tanto como hacer lo propio con los revolucionarios y demás portadores de los errores modernos. La obra histórica de Rivera era peligrosa porque propiciaba la "confusión de ideas", cuya consecuencia, siempre según el censor, "nos llevaría inevitablemente al escepticismo, al indiferentismo, y a la impiedad volteriana y enciclopedista". ${ }^{54}$

El discurso histórico de Rivera era, pues, visto como potencialmente revolucionario por ese esfuerzo de llevar a los aztecas al cielo, pero cabe repetir que la representación que el autor laguense hacía de los pueblos prehispánicos mediante su crítica de la leyenda de Papantzin tampoco estaba libre de la superstición que hemos visto en los otros historiadores liberales -o mejor dicho, del fanatismo en el caso concreto del Compendio-. Si los cronistas novohispanos integraban a esos pueblos al relato de la historia salvífica por medio de la princesa resucitada, dejando en el olvido a la antigua mensajera de Tláloc, los liberales decimonónicos más bien racionalizaban con él la derrota de los aztecas en el siglo xvI, casi se diría que proyectando hacia el pasado sus prejuicios contra lo popular y religioso. En todos estos textos, además, se pierde el interés en la ejemplaridad de la virtuosa princesa, antes al contrario, lo mejor que podían decir

53 Rivera, Tres documentos, pp. 3-4.

54 Rivera, Tres documentos, p. 12. 
los historiadores es que era una víctima de la catalepsia, y lo peor - de nuevo fue el caso del autor laguense-, directamente que estaba loca.

A pesar de todo ello, al mismo tiempo que los historiadores casi trataban de enterrar de nuevo a la princesa, había también otros escritores que la resucitaron nuevamente para la cultura nacional. Uno de ellos, José María Marroquí, fue tanto literato como cronista de la ciudad de México, y ya en los albores del siglo $\mathrm{xx}$ fue tal vez el único que trató de indagar nuevos datos sobre la princesa. Paradójicamente, lo que encontró fue que ni siquiera sus posibles descendientes ${ }^{55}$ conservaban memoria de ella, aunque al menos identificó la que habría sido su casa después de la conquista, en el callejón del Coyote, antiguo barrio de San Salvador Coatlán. ${ }^{56}$ Asimismo, la crítica de los historiadores no evitó que el "memorable suceso de la princesa Papantzin" apareciera en textos destinados a la educación básica, lo mismo de tiempos de la República Restaurada que todavía tras la Revolución, y desde luego está incluida entre las Mujeres notables mexicanas de Wright de Kleinhans (quien por ello es la primera autora que podemos incluir aquí), siguiendo fielmente lo que aparece en las crónicas novohispanas y en las observaciones de Orozco y Berra..$^{57}$ Mas a partir de entonces la princesa resucitada se ha ido ausentando de los textos históricos, para aparecer fundamentalmente en la literatura como una leyenda.

\section{PERSONAJE DE LEYENDA}

Aunque no aparecía aún en la traducción de la obra de Prescott, precisamente es en torno a la década de 1840 cuando comienza a

${ }_{55}$ En todo caso descendían de doña Vicenta Mir y Papantzin, esposa de don Francisco Morejón, oriundo del reino de Sevilla.

${ }^{56}$ Marroquí, La Ciudad de México, t. 2, p. 377.

57 Mendoza y Romo, Nociones de cronología, p. 274. Subdivisión de los programas, p. 122. WRIGHT DE KLEINHANs, Mujeres notables, pp. 31-35. 
resemantizarse el término “leyenda”. Hasta entonces no refería sino a "materia que se lee" o a "inscripción”, y a partir de entonces comenzó a significar también "sucesos históricos o fabulosos” que databan de antaño. Así aparece ya en el diccionario de Salvá de 1846, donde se acota que se trataba de un neologismo: “ahora se da este nombre [...]”, comenzaba la nueva entrada del término. ${ }^{58}$ La profecía de la princesa resucitada se transformó entonces en leyenda con ese doble carácter, negativo en tanto historia fabulosa y positivo en tanto historia tradicional.

A mediados del siglo XIx, la representación de la princesa resucitada más semejante a lo que hemos visto en los cronistas novohispanos aparece en el "Canto de Papantzin” de Miguel A. O’Gorman, autor del que hasta ahora no hemos encontrado más información. Conforme a su título, se trata de la propia princesa exaltando la grandeza divina celestial, en contraste con la humildad de su propio ser terrenal, comparable a un "gusano de tierra deleznable” y al “frágil grano de arena”. En estos versos, además, reaparecen las alusiones a la vocación monacal, con la voluntad del aislamiento en servicio exclusivo de Dios y con la intercesión en favor de su pueblo y su hermano. ${ }^{59}$

Pero esos versos son excepcionales, pues en esta nueva resurrección de su figura, Papantzin, si bien conservó sus virtudes cristianas, más bien acumuló otras más seculares. Las dos más notorias fueron la belleza y la dependencia emocional de un hombre: su marido. En su versión más remota, en los Primeros memoriales, había sido asesinada por la violencia machista, diríamos hoy, concretamente a consecuencia de una agresión de su suegro. En las crónicas, sin embargo, su muerte se había debido a una "grave enfermedad". ${ }^{60}$ En el siglo XIX, de nuevo era la relación con un hombre lo decisivo,

58 Salvá, Nuevo diccionario de la lengua, p. 659.

59 El Eco de Ambos Mundos, pp. 179-181.

60 Torquemada, Monarquía indiana, p. 324. 
pues pasó a vincularse con la melancolía causada por la viudez. Así lo vemos ya en los Recuerdos de Anábuac (1852) del joven Emilio Rey, quien hizo de ella una mujer "más gallarda que la altiva palma”, insinuó una descripción ligeramente erótica del cuerpo de la resucitada, e insistió en el vínculo con el marido fallecido "en quien miraba un cielo", el "que fue su ilusión y su tesoro", hasta que "murió la hermosa de dolor transida". ${ }^{61}$ Dos décadas más tarde, la melancolía fatal de la viuda se reitera en Los mártires del Anábuac de Eligio Ancona, quien atribuyó su muerte a que "continuó viviendo en el palacio de su marido" pues "le hacía tener siempre presente la memoria del hombre que había amado". ${ }^{62}$ Asimismo aparece en los Romances históricos mexicanos de José Peón Contreras (1873): "Y fue su pesar tan hondo / en tan aflictivo lance, / que con la viudez llegaron / padecimientos y achaques, / Sin que valieran remedios / contra sus físicos males, / que el daño estaba en el alma / y ésta no es fácil que sane". ${ }^{63}$

Un poco más original, José María Roa Bárcena en sus Leyendas mexicanas (1862) le agregó a la princesa otra virtud cristiana, la caridad, y hasta ahora es el único autor que he identificado que le atribuyó inteligencia para asuntos públicos, siempre en su calidad de hermana del emperador. "Fiel dechado de hermosura y bondad", habría sido "tan discreta y hábil la princesa que a veces el monarca la consulta, / Y ella a regir el mexicano imperio / con talento clarísimo le ayuda”. Por ello el emperador Moctezuma la habría llorado diciendo "Sabiduría y caridad con ella / desaparecen para siempre juntas" ${ }^{64}$

Sin embargo, tal vez la representación más interesante de la princesa en las décadas finales del siglo xix fue la de José María

61 Rey, Recuerdos de Anábuac, pp. 17-19.

62 Ancona, Los mártires del Anábuac, p. 118.

63 Peón, Romances históricos, p. 137.

64 Roa Bárcena, Leyendas mexicanas, pp. 152-153. 
Marroquí en su obra La llorona (1887). ${ }^{65}$ Desde luego, Papantzin se convierte en el reverso de la protagonista de la historia, que no es otra sino Malinche o Marina, mujer condenada a vagar por las calles de la ciudad de México todas las noches por 300 años para expiar la culpa de la traición. ${ }^{66}$ Frente a esa pecadora penitente y arrepentida, se erige la princesa "dechado completo de virtudes civiles y cristianas", constantemente descrita como "tierna", "piadosa", "compasiva", "prudente” y "sensible". Pero es virtuosa de una forma diferente del relato de Torquemada. Lo más obvio es que no se trata de una mujer enclaustrada, Marroquí no tuvo ningún problema en describirla saliendo de su casa en medio de la noche para ir al encuentro de Marina, ni en que se convirtiera en su compañera permanente de penitencia. Esto es, no se trata de un personaje de vida contemplativa, pues su "primer móvil" era una "ardiente caridad". ${ }^{67}$

Cabe recordar que la obra de Marroquí tenía propósitos explícitamente didácticos, y era asimismo muy clara en su propósito de difundir ciertos conocimientos e inculcar ciertos valores; la caridad era uno de ellos. Esto se nota sobre todo en el diálogo que las dos protagonistas sostienen durante la noche quinta, ${ }^{68}$ cuando Papantzin se ofrece a acompañar cada noche a Malitzin y ésta trata de disuadirla proponiéndole un acompañamiento únicamente espiritual; la princesa responde diciendo que "oración, ayuno, cilicios, disciplina, el perpetuo retiro a la soledad de un claustro" eran "efectos de la virtud egoísta", ${ }^{69}$ e incluso los actos de culto eran contrastados con los méritos de una "sublime caridad", que ya en palabras de la

\footnotetext{
65 Agradezco a la doctora Rosa María Spinoso Arcocha haberme recomendado esta obra.

66 Marroquí, La llorona, p. 95.

67 Marroquí, La llorona, pp. 15 y 66.

68 Marroquí, La llorona, pp. 98-102.

69 Marroquí, La llorona, p. 98.
} 
propia Malitzin, "es la que con voluntad decidida se hace en medio del mundo y de la sociedad". ${ }^{70} \mathrm{El}$ autor, desde luego, no hacía sino respaldar un cambio en el modelo de mujer católica que la historiografía había señalado ya: en lugar de la devota de siglos anteriores, se favorecía la participación activa en la beneficencia. ${ }^{71}$

En suma, la Papantzin cuasi-monjil se secularizaba, en el sentido más tradicional del término, para convertirse en una amante devota hasta la muerte y en una auténtica dama de la caridad. Cabe reconocer que su nombre también fue usado como seudónimo por una de las escritoras del periódico Las Hijas del Anábuac, de contenido más reivindicativo de la situación de las mujeres, aunque hasta donde sabemos fue en una única ocasión. ${ }^{72}$ Además, como se puede advertir ya en los títulos de las obras que he venido citando en este apartado, Papantzin cambiaba de lugar. Aquí no tratamos directamente con obras de historia, sino de literatura nacional. Los Recuerdos de Anábuac de Emilio Rey eran una colección de cuatro "cantos históricos mexicanos" dedicados al historiador José Fernando Ramírez. En la nota dirigida al entonces también ministro de Relaciones, el autor afirmaba que su "único mérito" no era literario, sino contribuir a la construcción de la memoria histórica nacional (diríamos hoy), al "bosquejarse en ellos acciones heroicas y nobles hechos de esforzados guerreros". ${ }^{73}$ Esos adjetivos hacían ver que se trataba además de una literatura necesariamente didáctica, como hemos visto, que proponía ejemplos a imitar. Lo hacía más explícito José María Roa Bárcena (1862), quien en el prólogo de su obra tomaba distancia de las compilaciones poéticas de "cuitas privadas y personalísimas" en beneficio de

70 Marroquí, La llorona, p. 101.

${ }^{71} \mathrm{Al}$ respecto baste remitir a los trabajos de Arrom, "Las señoras de la caridad" "La movilización de las mujeres".

72 Papantzin, "La mujer”, Las hijas del Anábuac, 2 (26 oct. 1873), p. 1.

${ }^{73}$ ReY, Recuerdos de Anábuac, p. 3. 
las dedicadas a "la exposición y la acción de las costumbres, tradiciones y pasiones humanas" de las cuales "se desprende alguna enseñanza histórica, moral o religiosa". ${ }^{74}$ Esto es, era una literatura patriótica, que recuperaba hechos o leyendas del pasado, los presentaba de forma poética y pretendía así contribuir a la educación de quienes integraban la nación mexicana.

Ya desde unos años antes el relato había llegado a las escuelas, pues aparece en el Simón mexicano (1868), asociado con el cerro de Chapultepec, pues "en este lugar pasó la escena aterradora que refiere la tradición azteca" de la "princesa mexicana" que sale de su tumba. Como en las crónicas, todavía podía inspirar "sentimientos de terror", y aunque no era una obra de historia, sobra decir que aquí - como en todas las anteriores - se daba por válido un origen efectivamente prehispánico. ${ }^{75}$

A más de la literatura nacional, gracias a Widdifield y Lecouvey, ${ }^{76}$ sabemos que en esta misma época las Leyendas mexicanas de Roa Bárcena dieron tema a concursos de pintura académica nacionalista, de los que resultaron al menos dos obras que representaban la historia de la princesa: La princesa Papantzin (1881) de Juan Urruchi, y de Isidro Martínez (1893) La resurrección de la princesa Papantzin, conservada en el $\mathrm{Mu}-$ seo de Bellas Artes de Toluca. El segundo de ellos representa precisamente el encuentro de la princesa con su mayordoma; conforme a la crónica de Torquemada, Papantzin aparece sentada a la orilla de una alberca, iluminada por el sol, y la otra mujer, en las sombras, cayendo a sus pies y tratando de evitar dirigir la mirada hacia la que estimaba como aparición fantasmal.

Embellecida en los versos y con el pincel de los artistas conforme a las convenciones decimonónicas, convertida en mujer ejemplar para los valores de esta nueva época, la revaloración

74 RoA BÁrcena, Leyendas mexicanas, pp. 5-6.

75 Simón mexicano, pp. 103-104.

76 Widdifield, “Dispossession, Assimilation, and the Image”, pp. 130-132; Lecouvey, “'Nos ancêtres les Aztèques’?”, pp. 134-135. 
de la princesa Papantzin no dejaba de tener sus ambigüedades. Como ha observado Lecouvey, ${ }^{77}$ no se trataba sino de construir unos "antiguos mexicanos", "con todas las características del mexicano ideal", y no de reivindicar a las civilizaciones prehispánicas ni mucho menos a los “indios” reales. Paradójicamente, a pesar de toda la afición que le demostraron los intelectuales del Porfiriato, hasta donde he podido averiguar, la leyenda de Papantzin no llegó a integrarse a las celebraciones patrióticas del centenario del inicio de la guerra de independencia, realizadas en 1910. En cambio, con motivo del centenario de la consumación de la independencia, en 1921, el poeta y político Alfonso Cravioto le dedicó nuevos versos desde las páginas del periódico $E l$ Universal -el mismo diario que organizó el célebre certamen de la India bonita- ${ }^{78}$ que constituyen el cierre del ciclo que examinamos aquí.

En esta última versión versificada de su resurrección, la princesa vuelve a ser la profetisa de la conquista, siempre conforme al relato de Torquemada, pero ahora presenta su visión embargada de tristeza: "no lloraban sus ojos, mas su voz sí lloraba", "así habló la princesa, con voz que desolaba". Más todavía, lejos de representarla expectante de la religión verdadera, Cravioto la describe ante todo consciente del oscuro porvenir que se aproxima: "vuelvo a la vida con presagios de muerte;/ nuestro rey verá pronto su corona perdida,/ destrozado su imperio, y angustiada su suerte". El ángel insiste en anunciar, antes que la llegada de la nueva religión a tierras americanas, el inicio de un momento de extrema violencia: los españoles, "entre horror y amarguras / harán un nuevo reino sobre sangrientos charcos $[\ldots]$ guerra y estragos han de llegar primero". Papantzin recibe el mensaje en medio de un "terror profundo", al igual que su hermano, casi sobra decir; de forma que Cravioto concluye

77 Lecouvey, Nos ancêtres les Aztèques?, p. 137.

78 Gonzales, "Modernity and the Indigenous", pp. 48-50. 
presentando la escena del emperador que "mira hacia el oriente con trágica tristeza".$^{79}$

\section{COMENTARIOS FINALES}

En 1921 existía ya otra princesa nahua legendaria que vendría, de cierta forma, a reemplazar a Papantzin en tiempos de la consolidación del régimen posrevolucionario: Iztaccíhuatl, princesa convertida en montaña, compañera de Popocatépetl, que desde la década de 1870 había comenzado a ser tema de leyenda para los intelectuales mexicanos hasta alcanzar una versión definitiva en los versos de José Santos Chocano. ${ }^{80}$ Aunque, como hemos visto al final, todavía era posible recuperarla en conmemoraciones patrias, no dejaba de ser una figura demasiado cargada de herencia católica y novohispana. Acaso por ello a partir de entonces dejamos de encontrarla en obras nacionales y resulta más común ver a la resucitada en obras literarias extranjeras, como en el caso de Salvador de Madariaga, o en cualquier caso en textos que ya no tenían relación directa con el Estado. ${ }^{81}$

Al final de este recorrido, cabe ante todo reiterar el interesante entrecruzamiento de problemáticas que caracteriza la historia de la princesa Papantzin, en que lo mismo hemos distinguido cambios en los modelos de género femenino, en las representaciones de los pueblos prehispánicos y en el estatuto de su relato, de profecía a leyenda. El relato de la mujer que volvió de la tumba, como puede verse, lo mismo ha servido para la legitimación de la conquista que para exaltar el nacionalismo mexicano. Sin embargo, tal vez la más grande paradoja de esta ya larga serie de textos recorridos, es que detrás de ellos es casi imposible que haya habido una mujer de carne y hueso, mucho

79 Todas las citas proceden de Cravioto, Poesías completas, pp. 222-223.

80 El poema adquirió carta de naturalización en la enseñanza en México con su inclusión en la obra de Mistral, Lecturas para mujeres, pp. 122-124.

81 Madariaga, El corazón. 
menos que se hubiera llamado efectivamente Papantzin. Como hemos visto, aunque el relato tiene su referente más remoto en la historia de Quetzalpétlatl, que podría tener elementos prehispánicos, tampoco podemos confirmarlo con plena seguridad. En ese sentido, nuestra protagonista no es sino un personaje efectivamente mítico, sujeto, como hemos visto, a los intereses de cronistas, historiadores y literatos, siempre varones - apenas hemos mencionado a dos mujeres en todo nuestro recorrido-, y en realidad poco interesados en imaginar siquiera qué era ser una mujer en la civilización mesoamericana.

La princesa, en suma, ilustra así de manera particular el proceso de secularización. Esto no sólo porque Papantzin salió de su enclaustramiento en el siglo xix, como ya hemos señalado, sino porque en realidad no es sino un elemento de la mitología cristiana que fue trasladado a los nuevos ámbitos de la historia y de la cultura nacionales, según era necesario, para terminar siendo abandonado casi por completo después de 1921, en aras de nuevos modelos.

\section{REFERENCIAS}

Alamán, Lucas y otros, Diccionario universal de historia y de geografía, México, Imprenta de F. Escalante y compañía, Librería de Andrade, 1854, t. V.

Ancona, Emilio, Los mártires del Anábuac, novela histórica, México, José Batiza editor, 1870, vol. I.

Anderson, Arthur J. O., "Los 'Primeros Memoriales' y el Códice Florentino", en Estudios de Cultura Nábuatl, 24 (1994), pp. 49-91.

Aquino, Tomás de, Suma teológica, http://hjg.com.ar/sumat/index.html Consultado el 15 de enero de 2020.

Arrom, Silvia M., "Las señoras de la caridad: pioneras olvidadas de la asistencia social en México, 1863-1910”, en Historia Mexicana, Lvi: 2 (226) (2007), pp. $445-490$. 
Arrom, Silvia M., "La movilización de las mujeres católicas en Jalisco. Las señoras de la caridad, 1864-1913”, en Porter y Fernández, 2015, pp. 67-92.

Azuela, Mariano, El padre Agustín Rivera, México, Botas, 1942.

Baranda, Joaquín, Obras del licenciado Joaquín Baranda, México, Victoriano Agüeros editor, 1900.

BASCHET, Jérôme, La civilización feudal. Europa del año mil a la colonización de América, México, Fondo de Cultura Económica, 2009.

Bernard, Carmen y Serge Gruzinski, De la idolatría. Una arqueología de las ciencias religiosas, México, Fondo de Cultura Económica, 1992.

Bustamante, Carlos María, Mañanas de la Alameda de México, México, Imprenta de la testamentaria de Valdés, 1836, t. II.

Clavijero, Francisco X., Historia antigua de México y de su conquista, México, Imprenta de Lara, 1844.

Cravioto, Alfonso, Poesías completas, 1904-1944, México, Poesía Hispanoamericana, 1971.

El Eco de Ambos Mundos. Periódico literario dedicado al bello sexo, México, Imprenta en la calle de Tiburcio, 1874.

Gleghorn, Charlotte y Helen Gilbert (eds.), Recasting Commodity and Spectacle in the Indigenous Americas, Londres, School of Advanced Studies, 2014.

Gomez, Thomas (ed.), École, culture et nation, París, Université Paris Ouest Nanterre La Défense, 2011.

Gonzales, Michael J., "Modernity and the Indigenous in Centennial Celebrations of Independence in Mexico City, 1910 and 1921", en Gleghorn y Gilbert, 2014, pp. 37-54.

Johansson, Patrick, "La Ley de Topiltzin. Fundamentos mitológicos del protocolo ritual en las exequias de los señores de Anáhuac", en Estudios de Cultura Nábuatl, 50 (2015), pp. 91-182.

Lafragua, José María, “Ciudad antigua de México”, en Alamán y otros, 1854, t. V, pp. 784-791. 
Lecouvey, Marie, “'Nos ancêtres les Aztèques'? Représentations du passé préhispanique et de la conquête à l'Académie des Beaux-Arts de Mexico, 1861-1911 : entre patriotisme et racisme”, en Gomez (ed.), 2011, pp. 107-144.

Le Goff, Jacques, La naissance du Purgatoire, París, Gallimard, 1981.

León Portilla, Miguel, Bernardino de Sahagún. Pionero de la antropología, México, Universidad Nacional Autónoma de México, El Colegio Nacional, 1999.

León Portilla, Miguel, “Biografía de fray Juan de Torquemada”, en TorQUEMADA, 1975, vol. vII, pp. 13-48.

López Austin, Alfredo, "Estudio acerca del método de investigación de fray Bernardino de Sahagún”, en Estudios de Cultura Nábuatl, 42 (2011), pp. $354-400$.

López Meraz, Óscar Fernando, "Discursos historiográficos sobre la figura del indio mesoamericano en el siglo xvi y la obra de fray Bernardino de Sahagún”, en Lusitania Sacra, 25 (2012), pp. 19-32.

López Meraz, Óscar Fernando, "Imaginario franciscano en Nueva España, siglo xvi: demonio, paraíso terrenal, seres fantásticos y sucesos maravillosos", en Amerika, 11 (2014). http://journals.openedition.org/amerika/6353 Consultado el 30 de abril de 2019. DOI: 10.4000/amerika.6353

Madariaga, Salvador de, El corazón de piedra verde, Buenos Aires, Sudamericana, 1959.

Marroquí, José María, La llorona. Cuento histórico mexicano, México, Imprenta de Ignacio Cumplido, 1887.

Marroquí, José María, La Ciudad de México, México, Tipografía y litografía La Europea, 1900, t. III.

Mendoza, Eufemio y Manuel A. Romo, Nociones de cronología universal extractadas de los mejores autores para los alumnos de las escuelas de instrucción secundaria, México, Imprenta del Gobierno, 1874.

Mistral, Gabriela, Lecturas para mujeres destinadas a la enseñanza del lenguaje, México, Secretaría de Educación Pública, 1924. 
Orozco y Berra, Manuel, Historia antigua y de la conquista de México, México, Tipografía de Gonzalo A. Esteva, 1880, t. III.

Peón Contreras, José, Romances históricos mexicanos, México, Díaz de León y White, 1873.

Porter, Susie y María Teresa Fernández, Género en la encrucijada de la historia social y cultural de México, México, El Colegio de Michoacán, Centro de Investigaciones y Estudios Superiores en Antropología Social, 2015.

Prescott, William, Historia de la conquista de México, México, Ignacio Cumplido impresor, 1844, t. I.

Prieto, Guillermo, Lecciones de historia patria, México, Imprenta de la Escuela Correccional, 1896.

Ragot, Nathalie, "Mémoire espagnole et mémoire indienne dans un présage aztèque”, en Journal de la Société des Américanistes, 89-1 (2003), pp. 9-20. http://journals.openedition.org/jsa/3703 Consultado el 30 de abril de 2019. DOI: $10.4000 /$ jsa.3703

Ramírez, José Fernando, Bautismo de Moteubzoma II, noveno rey de México. Disquisición histórico-crítica de esta tradición, México, Imprenta de A. Boix, 1864.

Rey, Emilio, Recuerdos de Anábuac. Colección de cantos históricos mexicanos, México, Imprenta de Vicente Segura Argüelles, 1852.

Rivera, Agustín, Compendio de la bistoria antigua de Grecia, San Juan de los Lagos, Tipografía de José Martín, 1874.

Rivera, Agustín, Concordancia de la razón y la fe, San Juan de los Lagos, Tipografía de José Martín, 1876.

Rivera, Agustín, Compendio de la historia antigua de México desde los tiempos primitivos hasta el desembarco de Juan de Grijalva, San Juan de los Lagos, Tipografía de José Martín, 1878.

Rivera, Agustín, Tres documentos sobre el tomo $1^{\circ}$. del Compendio de la historia antigua de México, Lagos de Moreno, Tipografía de Vicente Veloz, 1881.

RoA BÁrcena, José María, Leyendas mexicanas, México, editor Agustín Masse-Librería Mexicana, 1862. 
Rozat, Guy, Indios reales e indios imaginarios en los relatos de la Conquista de México, Xalapa, Universidad Veracruzana, Benemérita Universidad Autónoma de Puebla, Instituto Nacional de Antropología e Historia, 2002.

Rozat, Guy, Repensar la Conquista, Xalapa, Universidad Veracruzana, 2013, t. I. https://www.uv.mx/bdh/files/2014/08/Libro_Repensar-la-Conquista-I. pdf Consultado el 30 de agosto de 2019.

Sahagún, Bernardino de, Códice Florentino. Historia general de las cosas de Nueva España, manuscrito, 1577, 3 vols. https://www.wdl.org/es/item/10096/ Consultado el 15 de febrero de 2020.

SAHAgún, Bernardino de, Historia general de las cosas de Nueva España, México, Imprenta de Alejandro Valdés, 1829, t. II.

Sahagún, Bernardino de, Primeros memoriales, Norman, University of Oklahoma Press, 1997.

SAlvá, Vicente, Nuevo diccionario de lengua castellana, París, Vicente Salvá editor, 1846, http://buscon.rae.es/ntlle/SrvltGUILoginNtlle Consultado el 15 de enero de 2020.

Segundo Guzmán, Miguel Ángel, "Conquista y reinterpretación de las tradiciones vencidas”, en Rozat (coord.), 2013, pp. 41-55.

Segundo Guzmán, Miguel Ángel, Historia y mirada en las crónicas de América, Guanajuato, Universidad de Guanajuato, 2018.

Simón Mexicano, $5^{\text {a }}$. ed., México, Viuda e Hijos de Murguía editores, 1882.

Subdivisión de los programas detallados de Educación Primaria para las escuelas dependientes de la Dirección de Educación Primaria y Normal del Distrito Federal (sugestiones a los maestros), México, Talleres Linotipográficos de F. S. Soria, 1922.

Torquemada, Juan de, Monarquía indiana, México, Universidad Nacional Autónoma de México, 1975.

Widdifield, Stacie G., "Dispossession, Assimilation, and the Image of the Indian in Late-Nineteenth Century Mexican Painting", en Art Journal, 49: 2 (1990), pp. 125-132. 
Wright de Kleinhans, Laureana, Mujeres notables mexicanas, México, Tipografía Económica, 1910.

Zamacois, Niceto de, Historia de Méjico, desde sus tiempos más remotos hasta nuestros días, Barcelona, México, J. F. Parrés y Compañía, 1877, t. III. 
